\title{
Effect of Breast Self Examination Programme on Women's Awareness for Early Detection of Breast Cancer
}

\author{
Naglaa Mohammed Abd-Elaziz ${ }^{1}$; Hany Hassan Kamal ${ }^{2}$; Hanaa Abd-Elhady ${ }^{3}$
}

1. B. S.C in Nursing, Faculty of Nursing.

2. Professor of Obstetrics and Gynaecology, Faculty of Medicine, Minia University.

3. Lecturer of women health and obstetric Nursing, Faculty of Nursing, Minia University.

\begin{abstract}
Background: Breast self-examination is a self-inspection of the breasts, initially proposed as an intuitive, inexpensive, non-invasive, and universally accessible means of promptly identifying early-stage breast neoplasms. This study aims to evaluate the effect of breast self-examination programme on women's awareness for early detection of breast cancer. Research design: A quasi-experimental design was utilized for carrying out this study. The study subjects were included 100 women in an outpatient clinic in maternity and child Minia University Hospital. Data collection tools: Three tools were used; The first tool: A structured interviewing questionnaire which involved socio-demographic characteristics of the studied women and knowledge questions, The second tool: women's attitude Scale regarding breast self-examination; and the third tool: Women's practices Observational checklist regarding breast self-examination. Results: the main results showed that minority, majority and nearly one third of the studied sample had satisfactory knowledge, positive attitude and good practice pre-program increased to the most of them post-program regarding breast self-examination with highly statistically significant differences . Regarding relation between the educational level of the studies sample with their total knowledge levels regarding breast selfexamination pre/post-program, statistically, significant differences were present. Conclusion: women's knowledge and attitude practices level increased post breast self-examination program and educational level of them positively affect their knowledge pre/ post-program and their attitude and practices only in pre-program. An extensive breast self-examination program may help detect breast cancer by increasing women's knowledge, attitude, and practices toward applying it. Recommendation: Develop a regular periodic educational program for women to enhance their knowledge, attitude, and practices toward breast self-examination
\end{abstract}

Keywords: Breast Self Examination, Breast Cancer, Early Detection, Program, Women's Awarenes

\section{Introduction:}

Breast self-examination is one of the three tests that the American Cancer Society recommends helping detect breast cancer in its earliest stage by regularly examining how their breast normally feels and reporting any breast changes promptly to their health care providers. Breast SelfExamination is a cost-effective method of early detection of breast cancer, especially in resource developing countries. More than $90 \%$ of breast cancer cases can be detected by women themselves, stressing the importance of breast selfexamination (BSE) as the key breast cancer detection mechanism (Marhaeni et al., 2017).

Breast self-examination benefits women in two ways: women become familiar with both the appearance and the feel of their breast and detect any changes in their breast as early as possible. Breast self-examination is best performed after menses (day 5 to day 7 counting the 1 st day of menses as a day one) because women themselves detect many breast cancer, priority is given to teaching all women how and when to examine their breast (Febriyanti et al., 2018). Women who do breast self-examination make a significant contribution to the early identification of breast cancer and reduce cancer fatalities (Mohapatro et al., 2020).

Knowledge of BSE involves having information on signs of BC, BSE procedures, and performing BSE (Akpanekpo, 2017). Knowledge of BSE may also influence the attitude and practice of BSE (Iwuoha et al., 2021). Attitude is a settled way of thinking about BSE, which includes acceptance that BSE is necessary, all women should perform it, ready to encourage other people to get information,

P a g e | 132 practice it, and seek early medical care with any abnormalities (Udoh et al., 2020).

Breast self-examination practice makes the individual become familiar with the structure of her breast and be responsible for her health since detecting any abnormality will necessitate seeking early medical care (Black and Richmond, 2019).

Nurses play a unique role in alerting the community to the early detection of breast cancer as they usually have the closest contact with female patients. Nurses can use their knowledge of the health services to educate women about breast cancer risk factors and available breast cancer screening services and practices. Nurses play an important role in educating women about the importance of breast selfexamination and understanding the risk factors of breast cancer (Aynalem et al., 2019).

\section{Significance of the study:}

Breast cancer is the most common cancer among women, comprising $23 \%$ of the female cancers. One in eight women born today will be diagnosed with breast cancer at some time in her life. The incidence rate of breast cancer is rapidly increasing in developing countries due to increased life expectancy, growing urbanization, adoption of western lifestyle, particularly in younger women (Haque et al., 2016). About half of all breast cancer (BC) cases occur in developing countries, with a $43 \%$ mortality rate compared to $30 \%$ in developed countries (Eltwansy, 2018).

However, detection of breast cancer at an early stage improves treatment options, specific opportunities for treatment, and survival. Theoretically, a 95\% survival rate 
could be achieved if breast cancer was diagnosed early (Mohamed et al., 2016).

\section{Aim of the study:}

To evaluate the effect of breast self-examination programme on women's awareness for early detection of breast cancer.

\section{Research hypotheses}

$H$ 1: There is a significant difference between the pretest and posttest knowledge, attitude, practice level regarding breast self-examination on any woman.

$\mathrm{H}$ 2: There is a significant association between pretest knowledge, attitude, practice level regarding breast self-examination women with selected socio-demographic variables.

\section{Subjects and Method \\ Research design}

A quasi-experimental design was utilized for carrying out this study.

\section{Setting}

This study was conducted in an outpatient clinic in maternity and child Minia University Hospital. This hospital provides different services such as antenatal care services, follow-up of pregnant women during pregnancy, Laboring services, gynecological services, family planning services, pot care services, laboratory tests, and health education services. The investigator expected to receive many women searching for the effect of breast self-examination programs on women's awareness for early detection of breast cancer.

\section{Subjects}

The study subjects included all women who are all fulfilling inclusion criteria during the period of data collection.

\section{Inclusion Criteria:}

- All women at reproductive age from 18 to 49 years old.

- Women not diagnosed with breast cancer.

- Women who have a family history and genetic disease of breast cancer.

\section{Sample size:}

The sampling technique was utilized in this study. The study sample included 100 women of reproductive age in a rural area in Minia city according; the sample size was estimated according to the determination of the sample size is based upon the following sample calculation formula :

$$
n=\frac{t 2 x p(1-p)}{m 2}
$$

\section{Data collection tools:}

Three tools were used to collect the current data

The first tool: A structured interviewing questionnaire: it was designed by the researcher and consisted of two parts:

Part I: socio-demographic characteristics

It was used to assess socio-demographic characteristics of women such as age, level of education, occupation, income, marital status, ........etc.
Part II: women's knowledge regarding breast selfexamination questionnaire: to assess women's knowledge regarding breast self-examination, it included (10) items related to the definition of BSE, timing of its importance of BSE and abnormalities of it.........etc. (Fletcher, 2020).

\section{Scoring system:}

For knowledge outcomes, correct response and complete were scored as (Two ), correct response and incomplete were scored as ( one ), while incorrect and " don't know" responses were scored as (Zero ). The total knowledge score was 20 scores. Score $\leq 10 \quad(50 \%)$ classified as unsatisfactory level of knowledge, scores $>10$ ( $50 \%)$ classified as a satisfactory level of knowledge.

The second tool: women's attitude Scale regarding breast self-examination: to assess women's attitude regarding breast self-examination, it included (14) questions

\section{Scoring system:}

For attitude outcomes, responses agree taken (three) responses neutral taken (two), and responses disagree taken (one). The total attitude score was 42 . Scores $\leq 21$ classified as a negative attitude, scores $>21$ classified as a positive attitude.

The third tool: Women's practices Observational checklist The researcher developed it to assess women's practices regarding breast self-examination. It involves (15) steps, such as (inspection, palpation, palpate of lymph node, squeezing of nipples and......etc.

\section{Scoring system:}

For practice outcomes, correct responses scored as (one), while incorrect responses were (Zero). The total practice score was 15 . Scores $\leq 7.5$ classified as poor practice scores * 7.6 classified as good practice.

\section{Validity and Reliability:}

To establish validity, the questionnaire was piloted on a panel of 5 experts of Obstetrics and Gynecological staff and nursing professors who reviewed the instruments for clarity, relevance, comprehensiveness, understanding, applicability, and easiness. The tools tested for internal consistency by using Cronbach's alpha test to check the stability of the internal consistency of the women's knowledge, attitude, and practice tools were $0.791,0.815$, and 0.804 , respectively, which is considered good reliability.

\section{Pilot study}

A pilot study was conducted on ten women $(10 \%)$ to ascertain the clarity and comprehensiveness of the tools as well as to estimate the appropriate time required to fill the questionnaire; results of the pilot study illustrated that no refinements and modification needed, so the subject was included to the actual sample.

\section{Ethical consideration :}

An official written approval letter clarifying the purpose of the study was obtained from the Dean of Faculty of Nursing Minia University and Head Manager of Minia University Hospital as approval for data collection. 


\section{Data collection procedure:}

Written initial approval was obtained from the research committee of the Faculty of Nursing, Minia University. Tool I, II, and III were submitted to a jury of 5 experts in the field of women's health and obstetric nursing department to determine its applicability and content validity. The necessary modification was done

A group interview was done by the researcher to explain the nature and purpose of the study. Data collection tools were introduced to women to be filled. The time required for filling the questionnaire was stimmed after making the pilot study. It was relatively thirty minutes. All study sample required handout includes knowledge related to breast self-examination such as definition, timing, technique, and signs of abnormality.

The study's data collection took three months, starting at the beginning of April at the end of June 2021. The research attended at setting; 3 days/ week starting from 9 A.m. to 2 P.m. until the end of the previous predetermined period. The researcher met women in the waiting area in the group's average number 5 to 8 women. At first, the researcher obtained oral consent after explaining the aim of the study and explaining how to fill the tools.

The first tool structured interviewing questionnaire used to assess general characteristics obstetrical history and knowledge of breast self-examination of the women with clarifying any question. The third tool (observational cheek list) assessed women's practices and attitudes regarding breast self-examination within 25 to 30 minutes. The follow-up sessions were done after three months by the investigator to conduct this study.

\section{Statistical analysis of data}

The data obtained from the study tools were categorized, tabulated, analyzed, and data entry was performed using the SPSS software (statistical package for social sciences version (25.0). Descriptive statistics were applied (e.g., mean, standard deviation, frequency, and percentage). Tests of significance were performed to test the study hypotheses. A significant level value was considered when $\mathrm{p}<0.05$.

\section{Results}

Table (1): Frequency distribution of the studied sample regarding their socio-demographic characteristics $(n=100)$

\begin{tabular}{|c|c|c|}
\hline Items & No. & $\%$ \\
\hline \multicolumn{3}{|l|}{ Age/ years } \\
\hline $20-30$ & 28 & 28.0 \\
\hline $30-40$ & 72 & 72.0 \\
\hline Mean \pm SD & \multicolumn{2}{|c|}{$32.6 \pm 4.7$ years } \\
\hline \multicolumn{3}{|l|}{ Education level } \\
\hline Not read or write & 59 & 59.0 \\
\hline read and write & 16 & 16.0 \\
\hline Basic education & 7 & 7.0 \\
\hline Secondary education & 12 & 12.0 \\
\hline High education & 6 & 6.0 \\
\hline \multicolumn{3}{|l|}{ Occupation } \\
\hline Housewives & 70 & 70.0 \\
\hline Worker & 30 & 30.0 \\
\hline \multicolumn{3}{|l|}{ Marital status } \\
\hline Married & 91 & 91.0 \\
\hline Widow & 6 & 6.0 \\
\hline Divorced & 3 & 3.0 \\
\hline \multicolumn{3}{|l|}{ Income } \\
\hline Sufficient & 20 & 20.0 \\
\hline Insufficient & 80 & 80.0 \\
\hline \multicolumn{3}{|l|}{ Residence } \\
\hline Rural & 68 & 68.0 \\
\hline Urban & 32 & 32.0 \\
\hline
\end{tabular}

Table (1): shows that the mean age of the studied sample was $32.6 \pm 4.7$ years, $59.0 \%$ of them not read or write, $70.0 \%$ of them were housewives, $91.0 \%$ of them was married, $80.0 \%$ of them hadn't insufficient income, and $68.0 \%$ of them lives in a rural area. 


\section{Source of knowledge}

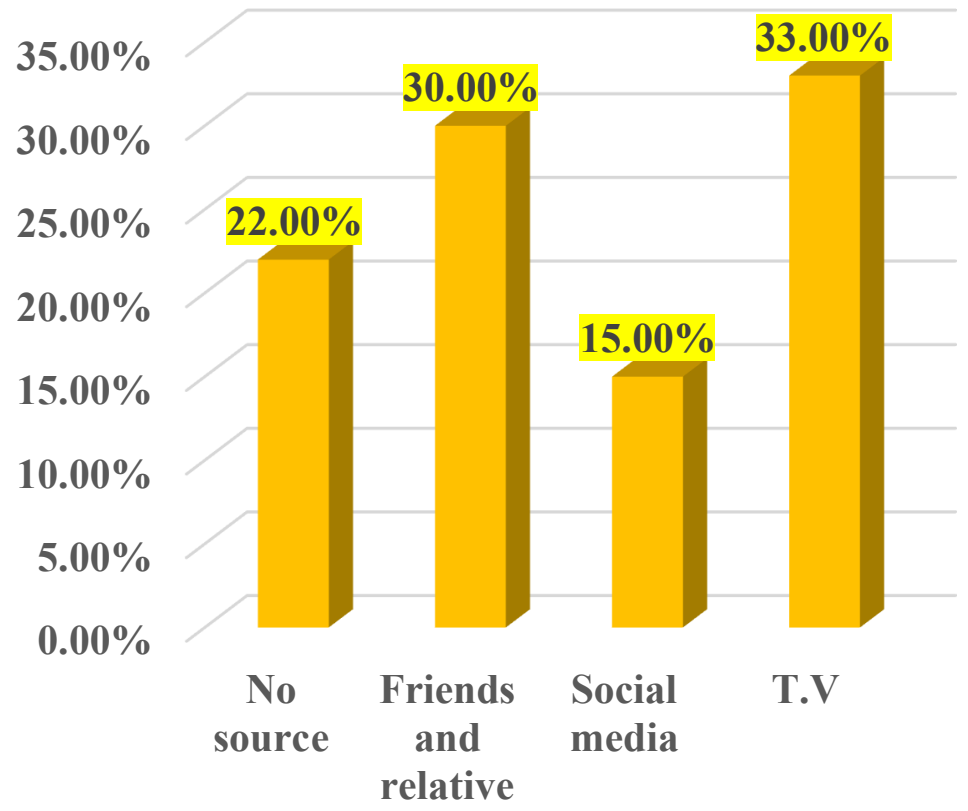

Figure (1): Percentage distribution of the studied sample regarding their sources of knowledge $(\mathrm{n}=100)$

Figure (1): illustrates that $33.0 \%$ of the studied sample their source of knowledge was television, followed by $30.0 \%$ of them was their friends and relative, $22.0 \%$ of them did not have any source of knowledge, and $15.0 \%$ of them their source was social media.

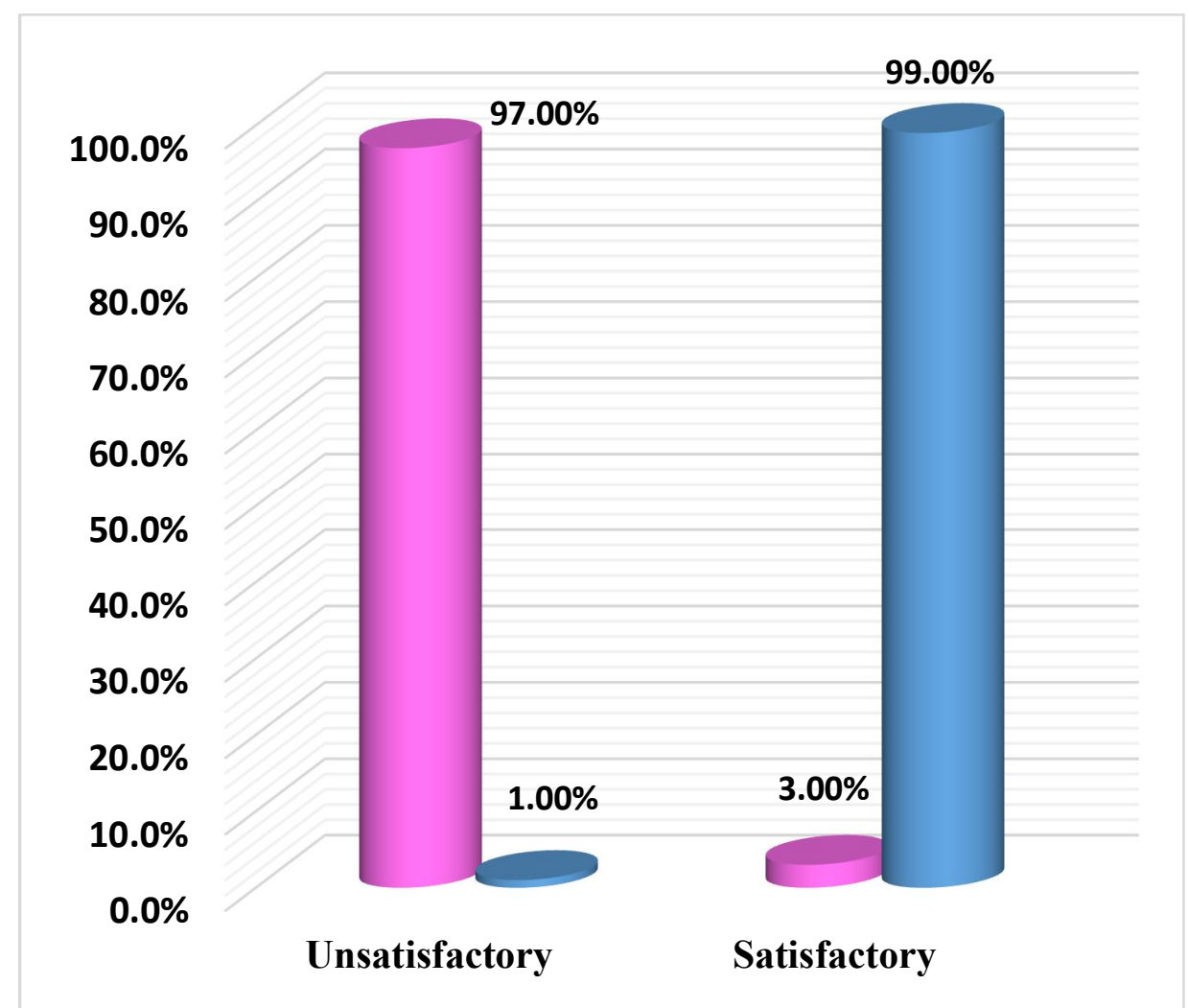

Figure (2): Percentage distribution of the studied sample regarding their total knowledge levels regarding breast selfexamination pre/ post program $(n=100)$.

Figure (2): illustrates that $3.0 \%$ of the studied sample had satisfactory knowledge regarding breast self-examination preprogram increased to $99.0 \%$ post-program with highly statistically significant differences which $P$-value $<0.0001$. 


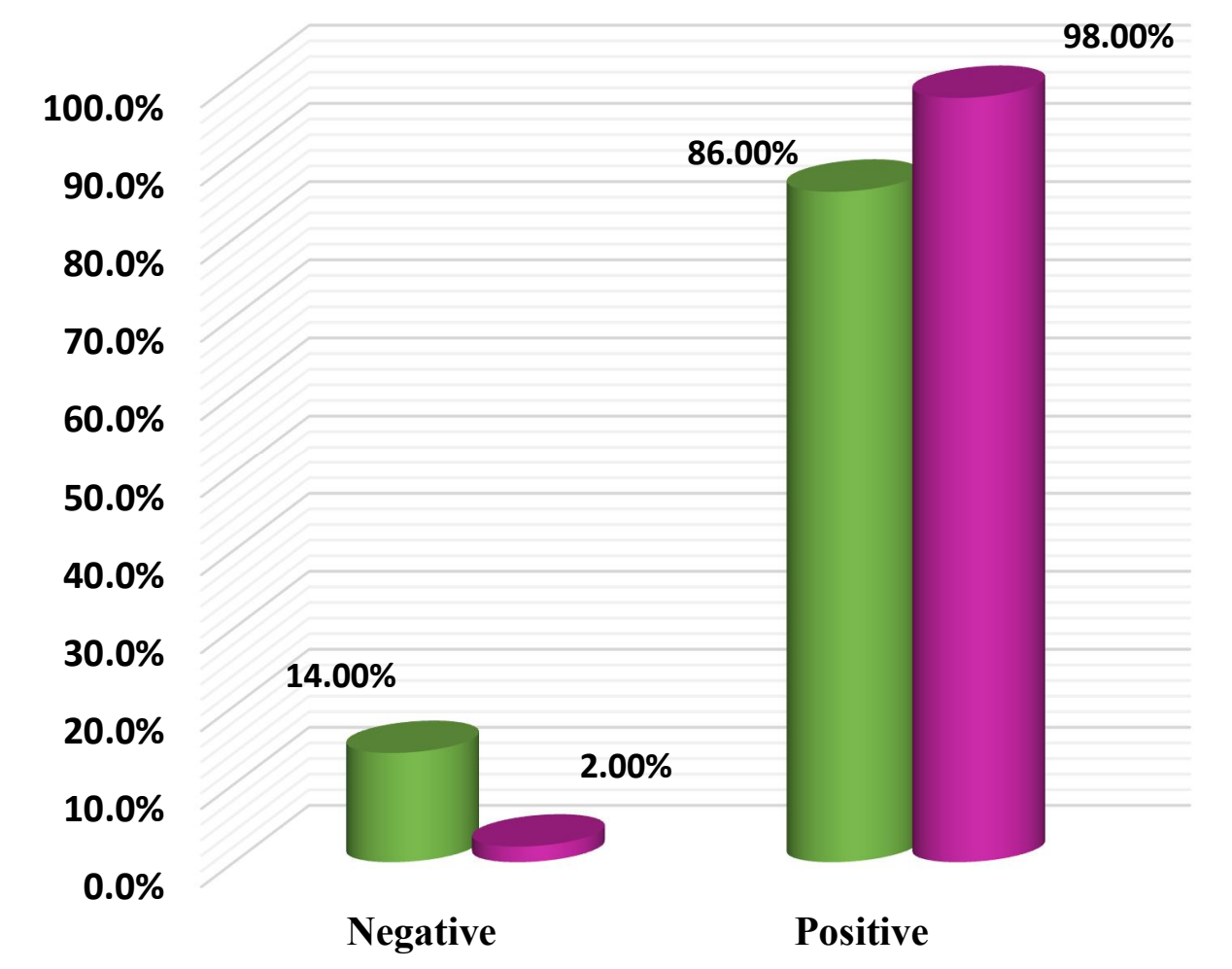

Figure (3): Percentage distribution of the studied sample regarding their total attitude levels regarding breast selfexamination pre/ post program $(n=100)$.

Figure (3) illustrates that $86.0 \%$ of the studied sample had a positive attitude regarding breast self-examination pre-program increased to $98.0 \%$ post program with highly statistically significant differences with $\mathrm{P}$-value $<0.002$.

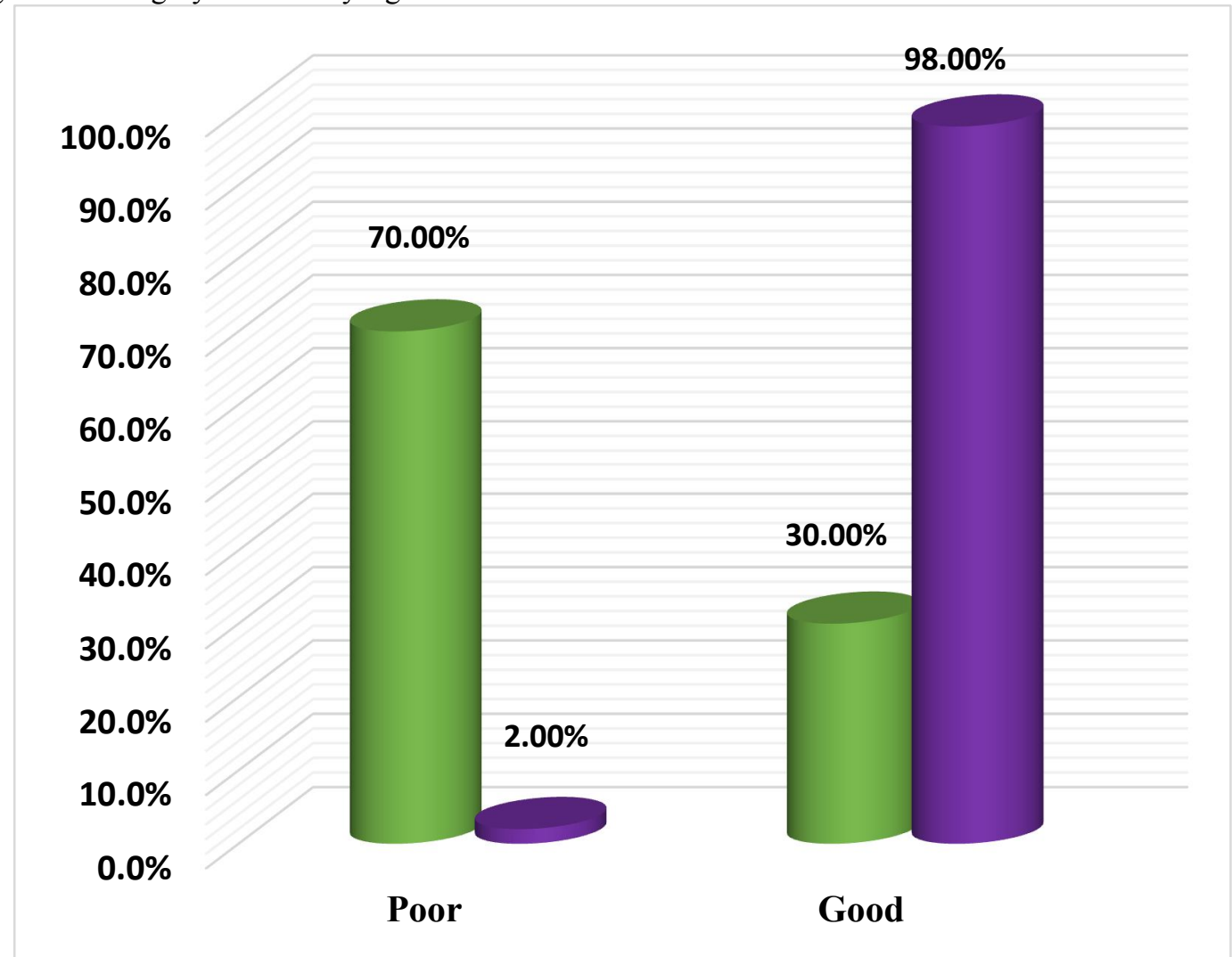

Figure (4): Percentage distribution of the studied sample regarding their total practice levels regarding breast selfexamination pre/ post program $(n=100)$.

Figure (4): illustrates that $30.0 \%$ of the studied sample had good practice regarding breast self-examination pre-program increased to $98.0 \%$ post-program with highly statistically significant differences which $\mathrm{P}$-value $<0.0001$. 
Minia Scientific Nursing Journal (Print - ISSN 2537-012X) (Online - ISSN 2785-9797) Vol. (10) No. (1) December 2021

Table (2): Relation between the socio-demographic characteristics of the studied sample and their total knowledge levels regarding breast self-examination pre/post-program $(n=100)$.

\begin{tabular}{|c|c|c|c|c|c|c|c|c|}
\hline \multirow[t]{3}{*}{ Items } & \multicolumn{4}{|c|}{ Total knowledge level (pre) } & \multicolumn{4}{|c|}{ Total knowledge level (post) } \\
\hline & \multicolumn{2}{|c|}{$\begin{array}{l}\text { Satisfactory }(n= \\
\text { 3) }\end{array}$} & \multicolumn{2}{|c|}{$\begin{array}{l}\text { Unsatisfactory }(n= \\
\text { 97) }\end{array}$} & \multicolumn{2}{|c|}{$\begin{array}{l}\text { Satisfactory }(n= \\
\text { 99) }\end{array}$} & \multicolumn{2}{|c|}{ Unsatisfactory $(\mathrm{n}=1)$} \\
\hline & No. & $\%$ & No. & $\%$ & No. & $\%$ & No. & $\%$ \\
\hline \multicolumn{9}{|l|}{ Residence } \\
\hline Urban & 3 & 9.4 & 29 & 90.6 & 32 & 100.0 & 0 & 0.0 \\
\hline Rural & 0 & 0.0 & 68 & 100.0 & 67 & 98.5 & 1 & 1.5 \\
\hline Fisher $(P-$ value $)$ & \multicolumn{4}{|c|}{$1.455(0.228)$} & \multicolumn{4}{|c|}{$0.475(0.491)$} \\
\hline \multicolumn{9}{|l|}{ Marital status } \\
\hline Married & 3 & 3.3 & 88 & 96.7 & 90 & 98.9 & 1 & 2.7 \\
\hline Widow & 0 & 0.0 & 6 & 100.0 & 6 & 100.0 & 0 & 0.0 \\
\hline Divorced & 0 & 0.0 & 3 & 100.0 & 3 & 100.0 & 0 & 0.0 \\
\hline Fisher $(P-$ value $)$ & \multicolumn{4}{|c|}{$2.962(0.451)$} & \multicolumn{4}{|c|}{$4.435(0.633)$} \\
\hline \multicolumn{9}{|l|}{ Education level } \\
\hline Not read or write & 0 & 0.0 & 59 & 100.0 & 58 & 98.3 & 1 & 1.7 \\
\hline read and write & 0 & 0.0 & 16 & 100.0 & 16 & 100.0 & 0 & 0.0 \\
\hline Basic education & 0 & 0.0 & 7 & 100.0 & 7 & 100.0 & 0 & 0.0 \\
\hline $\begin{array}{l}\text { Secondary } \\
\text { education }\end{array}$ & 0 & 0.0 & 12 & 100.0 & 12 & 100.0 & 0 & 0.0 \\
\hline High education & 3 & 50.0 & 3 & 50.0 & 6 & 100.0 & 0 & 0.0 \\
\hline Fisher $(P-$ value $)$ & \multicolumn{4}{|c|}{$8.537(0.05)^{*}$} & \multicolumn{4}{|c|}{$8.269(0.03)^{*}$} \\
\hline \multicolumn{9}{|l|}{ Occupation } \\
\hline Worker & 27 & 90.0 & 3 & 10.0 & 30 & 100.0 & 0 & 0.0 \\
\hline Housewives & 70 & 100.0 & 0 & 0.0 & 69 & 98.6 & 1 & 1.4 \\
\hline Fisher $(P-$ value $)$ & \multicolumn{4}{|c|}{$1.325(0.250)$} & \multicolumn{4}{|c|}{$0.433(0.511)$} \\
\hline
\end{tabular}

The percentage did by row *Statistically significance differences at $<0.05$

Table (2): shows that $50.0 \%$ of the highly educated studied sample had unsatisfactory knowledge regarding breast selfexamination pre-program with statistically significant differences which P-value $<0.05$ and no statistical significance difference between residence, marital status, and occupation of the studied sample with their total knowledge levels regarding breast selfexamination pre-program.

Also, $16.7 \%$ of the highly educated studied sample had satisfactory knowledge regarding breast self-examination postprogram with statistically significant differences, which P-value $<0.03$ and no statistically significant difference between residence, marital status, and occupation of the studied sample with their total knowledge levels regarding breast self-examination post-program.

Table (3): Relation between the socio-demographic characteristics of the studied sample and their total attitude levels regarding breast self-examination pre/post-program $(\mathrm{n}=100)$.

\begin{tabular}{|c|c|c|c|c|c|c|c|c|}
\hline \multirow[t]{3}{*}{ Items } & \multicolumn{4}{|c|}{ Total attitude level (pre) } & \multicolumn{4}{|c|}{ Total attitude level (post) } \\
\hline & \multicolumn{2}{|c|}{ Positive $(n=82)$} & \multicolumn{2}{|c|}{ Negative $(n=18)$} & \multicolumn{2}{|c|}{ Positive $(n=98)$} & \multicolumn{2}{|c|}{ Negative $(n=2)$} \\
\hline & No. & $\%$ & No. & $\%$ & No. & $\%$ & No. & $\%$ \\
\hline \multicolumn{9}{|l|}{ Residence } \\
\hline Urban & 22 & 68.8 & 10 & 31.3 & 32 & 100.0 & 0 & .0 \\
\hline Rural & 60 & 88.2 & 8 & 11.8 & 66 & 97.1 & 2 & 2.9 \\
\hline$X^{2} /$ Fisher $(P-$ value $)$ & \multicolumn{4}{|c|}{$5.597(0.018)^{*}$} & \multicolumn{4}{|c|}{$0.960(0.327)$} \\
\hline \multicolumn{9}{|l|}{ Marital status } \\
\hline Married & 79 & 86.8 & 12 & 13.2 & 89 & 97.8 & 2 & 2.2 \\
\hline Widow & 3 & 50.0 & 3 & 50.0 & 6 & 100.0 & 0 & 0.0 \\
\hline Divorced & 3 & 100.0 & 0 & 0.0 & 3 & 100.0 & 0 & 0.0 \\
\hline$X^{2} /$ Fisher $(P-$ value $)$ & \multicolumn{4}{|c|}{$14.134(0.0001)^{* *}$} & \multicolumn{4}{|c|}{$2.212(0.963)$} \\
\hline \multicolumn{9}{|l|}{ Education level } \\
\hline Not read or write & 50 & 84.7 & 9 & 15.3 & 58 & 98.3 & 1 & 1.7 \\
\hline read and write & 12 & 75.0 & 4 & 25.0 & 15 & 93.8 & 1 & 6.3 \\
\hline Basic education & 5 & 71.4 & 2 & 28.6 & 7 & 100.0 & 0 & 0.0 \\
\hline Secondary education & 10 & 83.3 & 2 & 16.7 & 12 & 100.0 & 0 & 0.0 \\
\hline High education & 5 & 83.3 & 1 & 16.7 & 6 & 100.0 & 0 & 0.0 \\
\hline Fisher $(P-$ value $)$ & \multicolumn{4}{|c|}{$3.577(0.545)$} & \multicolumn{4}{|c|}{$3.224(0.733)$} \\
\hline \multicolumn{9}{|l|}{ Occupation } \\
\hline Worker & 24 & 80.0 & 6 & 20.0 & 29 & 96.7 & 1 & 3.3 \\
\hline Housewives & 58 & 82.9 & 12 & 17.1 & 69 & 98.6 & 1 & 1.4 \\
\hline$X^{2} /$ Fisher $(P-$ value $)$ & \multicolumn{4}{|c|}{$0.116(0.733)$} & \multicolumn{4}{|c|}{$0.389(0.533)$} \\
\hline
\end{tabular}

Percentage done by row * * Statistically significance differences at $<0.05$

$* *$ Highly statistically significance differences at $<0.01$

Table (3): presents that $31.3 \% \& 50.0 \%$ of the urban and widow of the studied sample had negative attitudes regarding breast self-examination pre-program with statistically significant differences which $P$-value $<0.018,0.0001$ respectively but no statistically significant difference between educational level, and occupation of the studied sample with their total attitude levels regarding breast self-examination pre-program.

Also, no statistically significant difference between residence, marital status, educational level, and occupation of the studied sample with their total attitude levels regarding breast self-examination post-program. 
Minia Scientific Nursing Journal (Print - ISSN 2537-012X) (Online - ISSN 2785-9797) Vol. (10) No. (1) December 2021

Table (4): Relation between the socio-demographic characteristics of the studied sample and their total practice levels regarding breast self-examination pre/post-program $(n=100)$.

\begin{tabular}{|c|c|c|c|c|c|c|c|c|}
\hline \multirow[t]{3}{*}{ Items } & \multicolumn{4}{|c|}{ Total practice level (pre) } & \multicolumn{4}{|c|}{ Total practice level (post) } \\
\hline & \multicolumn{2}{|c|}{ Poor $(n=70)$} & \multicolumn{2}{|c|}{ Good $(n=30)$} & \multicolumn{2}{|c|}{ Poor $(n=2)$} & \multicolumn{2}{|c|}{ Good $(n=98)$} \\
\hline & No. & $\%$ & No. & $\%$ & No. & $\%$ & No. & $\%$ \\
\hline \multicolumn{9}{|l|}{ Residence } \\
\hline Urban & 14 & 43.8 & 18 & 56.3 & 2 & 6.3 & 30 & 93.6 \\
\hline Rural & 56 & 82.4 & 12 & 17.6 & 0 & .0 & 68 & 100.0 \\
\hline$X^{2} /$ Fisher $(P-$ value $)$ & \multicolumn{4}{|c|}{$15.441(0.0001) * *$} & \multicolumn{4}{|c|}{$4.337(0.037)^{*}$} \\
\hline \multicolumn{9}{|l|}{ Marital status } \\
\hline Married & 66 & 72.5 & 25 & 27.5 & 2 & 2.2 & 89 & 97.8 \\
\hline Widow & 1 & 16.7 & 5 & 83.3 & 0 & .0 & 6 & 100.0 \\
\hline Divorced & 3 & 100.0 & 0 & 0.0 & 0 & .0 & 3 & 100.0 \\
\hline$X^{2} /$ Fisher $(P-$ value $)$ & \multicolumn{4}{|c|}{$11.349(0.005) * *$} & \multicolumn{4}{|c|}{$3.475(0.324)$} \\
\hline \multicolumn{9}{|l|}{ Education level } \\
\hline Not read or write & 53 & 89.8 & 6 & 10.2 & 0 & 0.0 & 59 & 100.0 \\
\hline Read and write & 6 & 37.5 & 10 & 62.5 & 1 & 6.3 & 15 & 93.8 \\
\hline Basic education & 3 & 42.9 & 4 & 57.1 & 0 & 0.0 & 7 & 100.0 \\
\hline Secondary education & 7 & 58.3 & 5 & 41.7 & 0 & 0.0 & 12 & 100.0 \\
\hline High education & 1 & 16.7 & 5 & 83.3 & 0 & 0.0 & 6 & 100.0 \\
\hline$X^{2} /$ Fisher $(P-$ value $)$ & \multicolumn{4}{|c|}{$30.441(0.0001) * *$} & \multicolumn{4}{|c|}{$3.224(0.733)$} \\
\hline \multicolumn{9}{|l|}{ Occupation } \\
\hline Worker & 13 & 43.3 & 17 & 56.7 & 0 & .0 & 30 & 100.0 \\
\hline Housewives & 57 & 81.4 & 13 & 18.6 & 2 & 2.9 & 68 & 97.1 \\
\hline$X^{2} /$ Fisher $(P-$ value $)$ & \multicolumn{4}{|c|}{$14.512(0.0001) * *$} & \multicolumn{4}{|c|}{$0.875(0.350)$} \\
\hline
\end{tabular}

The percentage did by row $* *$ Highly statistically significant differences at $<0.01$

Table (4): shows that $56.3 \%$ of the urban studied sample had a good practice, $83.3 \%$ of the widow studied sample had a good practice, $83.3 \%$ of the high educational studied sample had a good practice, and $56.7 \%$ of the workers studied sample had good practice regarding breast self-examination pre-program with statistically significant differences which $P$-value $<0.0001,0.005$, $0.0001 \& 0.0001$ respectively.

Also, $100.0 \%$ of the urban of the studied sample had good practice regarding breast self-examination post-program with statistically significant differences, which P-value $<0.037$, but no statistically significant difference between marital status, educational level, and occupation of the studied sample with their total practice levels regarding breast self-examination postprogram.

\section{Discussion}

Breast self-examination (BSE) was a mainstay for decades in breast cancer screening recommendations. It is a self-inspection of the breasts, initially proposed as an intuitive, inexpensive, non-invasive, and universally accessible means of promptly identifying early-stage breast neoplasms (Pippin and Boyd, 2021). Breast self-examinations may note changes in the breasts during the cycle. The breasts become more lumpy and tender before menses and less lumpy and less tender after menses. The breast is usually easiest to examine on the days immediately following the menstrual cycle (Yeshitila et al., 2021). So, this study aimed to evaluate the effect of breast self-examination program on early detection of breast cancer

Concerning sources of the studied sample knowledge (figure 1), the most common of knowledge sources were television, followed by friends and relatives, and finally the social media. In the researcher point of view, might be due to the majority of the studied women lives in the rural area and not reading and writing and most information acquired from the television program

Regrading the studied sample total knowledge levels about breast self-examination pre/ post program (figure 2), the minority $(3.0 \%)$ of the studied sample had satisfactory knowledge regarding breast self-examination pre-program increased to the most of them post-program with highly statistically significant differences which P-value $<0.0001$. These findings might be explained by the studied sample's lower knowledge of the importance of BSE in early detection of $\mathrm{BC}$ pre-program and the fact that women are overburdened with their work and domestic responsibilities.
These results in the same line with study done by Padmaja et al. (2020), assessed the effectiveness of the awareness program on knowledge regarding breast cancer and practice on breast self-examination among rural women in Chittoor dist, Andhra Pradesh, reported that women had adequate knowledge after providing health education and skill training on BSE.

In addition, Almeldien et al. (2019) assessed the impact of a training program on improving knowledge and practices of rural community health workers regarding $\mathrm{BC}$ and BSE at Assiut Governorate, Egypt; there were highly statistically significant differences between total score of knowledge and practice during the three phases of the study pre, post, and follow-up test.

Also, Ahmed and Shrief (2019) evaluated the effect of a health promotion program on female BSE knowledge and practice at the surgical outpatient departments affiliated to Suez Canal University Hospitals and Beni-Suef University Hospitals, mentioned that in the pre-program phase, the level of satisfactory total knowledge about BSE is $20 \%$, while immediately after the program it is $90 \%$, and after one month of the program it is $80 \%$, with a statistically significant difference

Regarding the studied sample total attitude levels about breast self-examination pre/ post program (figure 3), found that the majority $(86.0 \%)$ of the studied sample was positive attitude regarding breast self-examination preprogram increased to the most of them $(98.0 \%)$ post-program with highly statistically significant differences which P-value $<0.002$. The increased level of knowledge and practices within the studied group may have changed attitudes about breast self-examination. 
This result is in the same line with a systematic review and meta-analysis done by Seifu and Mekonen (2021), who mentioned in general, urban resident tends to have positive attitudes toward and as well as better awareness about breast self-examination

Also, Alamin (2018) assessed the role of health education in raising university students' awareness in regard to the early detection of breast cancer (2011- 2013). Two hundred female students from third and fourth-class faculties of law and economics, Al Zaem Al Azhari University, Sudan, showed a positive attitude towards participation in a training educational program on breast cancer.

Regarding the studied sample total practice levels about breast self-examination pre/ post program (figure 4), found that nearly one third $(30.0 \%)$ of the studied sample had good practice regarding breast self-examination pre-program increased to most $(98.0 \%)$ of them post-program with highly statistically significant differences which P-value $<0.0001$. From the researchers' point of view, this might be connected to the influence of knowledge on practice, as increasing knowledge is associated with better selfconfidence, which in turn leads to the woman being able to practice with greater accuracy, in the opinion of the researchers.

This finding was consistent with many studies in different countries, as a study done by Alcan et al. (2021) evaluated the effects of BSE training on health beliefs and practices among relatives of nursing students, determined that more than one-third $(39.1 \%)$ of women performed BSE before the training and the majority $(87.2 \%)$ of them after the training and this difference was statistically significant

Also, a recent Egyptian study done by Mahmoud et al. (2020) evaluated the effect of the health belief modelbased education on breast cancer preventive behaviors conducted at the obstetrics outpatient clinic affiliated to Benha University Hospital, Egypt, mentioned that In the pre model implementation phase, $36 \%$ of the studied women had satisfactory practice, then this percentage improved to $74 \%$ post-model implementation.

Moreover, Almeldien et al. (2019) assessed the impact of a training program on improving practices of rural community health workers regarding $\mathrm{BC}$ and BSE at Assiut Governorate, Egypt; there were highly statistically significant differences between total score of practice during the three phases of the study pre, post, and follow-up test

Concerning the relation between the educational level of the studies sample with their total knowledge levels regarding breast self-examination pre/post-program, statistically, significant differences were present but no relation regarding age, residence, marital status, and occupation. It is possible that this is linked to women's academic achievement, which might assist them in gaining knowledge about breast self-examination.

This result was in the same line with Yılmaz et al. (2017), and Yoshany et al. (2016) showed a statistically significant difference between a score of knowledge and level of education in pre \& post-educational programs. While there wasn't a relationship between age and residence with a total score of knowledge.

Also, Güçlü S. and Tabak (2013) assessed the impact of health education on improving women's knowledge and awareness of breast cancer and BSE showed no statistically significant difference with participants' age and performance of BSE during three phases of the study.
Concerning the relation between the sociodemographic characteristics of the studied sample and their total practice levels, the current study showed that urban women, widows, educated and worked women had good practices regarding BSE pre-educational program and only urban women post educational program with statistically significant differences.

This finding in the same line with Mahmoud et al. (2020), evaluated the effect of the health belief model-based education on breast cancer preventive behaviors conducted at the obstetrics outpatient clinic affiliated to Benha University Hospital, Egypt; showed that a statistically significant association between women's total practice scores and their age, and educational level, pre and post model implementation. Also, there is a statistically significant association between the women's total practice score and marital status (pre model implementation) and residence pre model implementation.

Also, Ahmed and Shrief (2019) showed a highly significant relationship between socio-demographic variables and women's practice of BSE immediately after the program implementation, with most of the respondents, was the educational level of the studied sample.

\section{Conclusion:}

Women's knowledge and attitude practices level increased post breast self-examination program and educational level of them positively affect their knowledge pre/ post-program and their attitude and practices only in preprogram. Also, urban women, widows, educated and worked women had good practices regarding BSE pre-educational program and only urban women post educational program with statistically significant differences. An extensive breast self-examination program may help detect breast cancer by increasing women's knowledge, attitude, and practices toward applying it.

\section{Recommendations:}

- Develop a regular periodic educational program for women to enhance their knowledge, attitude, and breast self-examination practices.

- Increasing the number of health campaigns, multiplying TV shows, and health talks about breast self-examination will improve knowledge and hence attitude and practice.

- Further studies are implemented on a larger probability sample of women with different age groups.

\section{References}

(1) Ahmed, S. A. E. M., \& Shrief, S. E. (2019). The effect of health promotion program on female breast selfexamination knowledge and

(2) Akpanekpo EI. (2017). Knowledge, attitude, and practice of breast self-examination (BSE) among female undergraduates in the University of Uyo, southern Nigeria. Evo J Public Health; 2:6-11.

(3) Alamin Sh. M . The Role of Health Education in Promotion of Knowledge of Breast Self-Examination. ARC Journal of Public Health and Community Medicine; 3, (1), 26-33.

(4) Alcan, A. O., Cetin, S., \& Sezer, H. (2021). Effect of breast-self examination training on health beliefs and practices: student nurses educating relatives - progress in Health Sciences, 11(1), NA-NA. 
(5) Almeldien, H., Mohamed, H., Khalaf, S. A., \& Abdalfatah, W. H. (2019). Training Program for Rural Community Health Workers about Breast Self-Examination at Assiut Governorate, Egypt. American Journal of Nursing Research, 7(6), 983-990.

(6) Aynalem, A., \& Mebratu, A. (2019). Assessment of knowledge towards breast cancer early detection methods among female health professionals in Adigrat town public health institutions, Tigray, northern Ethiopia, 2018.

(7) Black E, and Richmond R. (2019). Improving early detection of breast cancer in sub-Saharan Africa: why mammography may not be the way forward. Glob Health;15(1):3.

(8) Eltwansy M.S. (2018). Early detection of breast cancer: knowledge, perception and barriers, The Egyptian Journal of Community Medicine, 36:11-22.

(9) Febriyanti, N. M. A., Lubis, D., Wirawan, D. N., Suariyani, N. L. P., \& Karmaya, M. (2018). The determinants of early breast cancer detection via breast self-examination (BSE) in Denpasar, Bali. Age (years), 35(57), 31-67.

(10) Fletcher S. W, (2020). Patient information: Risk factor for breast cancer. Up-To-Date. 2016

(11) Güçlü S. and Tabak R., (2013). Impact of health education on improving women's knowledge and awareness of breast cancer and Breast Self-Examination. The Journal of Breast Health, Vol. 9, No 1, P.p. 18-22.

(12) Haque, A.T.M.E., Hisham, M., Bin, M.A., Ahmad Adzman, NALB., Azudin NAB., Shafri, N.B., Haque, M. (2016). Cognizance and utilization about breast cancer screening among the health professional female students and staffs of University Kuala Lumpur, Royal College of Medicine Perak, Malaysia; 37:286-292.

(13) Iwuoha, E. C., Ekeleme, N. C., \& Uche, C. L. (2021). Knowledge, Attitude and Practice of Breast SelfExamination (BSE) among Women in an Urban City in Abia State, Nigeria. Asian Journal of Medicine and Health, $17-25$.

(14) Mahmoud, A. A., Abosree, T. H., \& Abd El Aliem, R. S. (2020). Effect of The Health Belief Model-Based Education on Preventive Behaviors of Breast Cancer. Evidence-Based Nursing Research, 2(4), 11-11.

(15) Marhaeni, G. A., Armini, N. W., Widhi Gunapria D, N., Putra Yasa, I., \& Choirul Hadi, M. (2017). The Breast SelfExamination (BSE) Behaviour among Balinese Women of
Reproductive Age. International Journal of Science and Research (IJSR), 6(10), 1818-1822.

(16) Mohamed, H., Ibrahim, Y., Lamadah, S. and Abo El-Magd, M. (2016). Application of the Health Belief Model for Breast Cancer Screening and Implementation of Breast Self-Examination Educational Program for Female Students of Selected Medical and Non-Medical Faculties at Umm al Qura University, Life Science Journal.13: 21-33.

(17) Mohapatro, P., \& Sahu, I. (2020). Effect Of Structured Teaching Programme On Knowledge Regarding Breast Self-Examination Among B. Sc Nursing Students. European Journal of Molecular \& Clinical Medicine, 7(11), 1126-1131.

(18) Padmaja, A., Mohanasundari, S. K., \& Kumar, K. S. (2020). Evaluate The effectiveness of Awareness programme with health Education on breast cancer and skill Training on breast self-Examination among rural women in chittoor Dist Andhra Pradesh-A Collaborative Research. Asian Journal of Nursing Education and Research, 10(1), 97-102.

(19) Pippin MM, and Boyd R. (2021. Breast Self Examination. [Updated 2021 Jul 1]. In: StatPearls [Internet]. Treasure Island (FL): StatPearls Publishing; 2021 Jan-. Available from: https://www.ncbi.nlm.nih.gov/books/NBK565846/

(20) Seifu, W., \& Mekonen, L. (2021). Breast self-examination practice among women in Africa: a systematic review and Meta-analysis. Archives of Public Health, 79(1), 1-17.

(21) Udoh, R. H., Tahiru, M., Ansu-Mensah, M., Bawontuo, V., Danquah, F. I., \& Kuupiel, D. (2020). Women's knowledge, attitude, and practice of breast selfexamination in sub-Saharan Africa: a scoping review. Archives of Public Health, 78(1), 1-10.

(22) Yeshitila, Y. G., Kassa, G. M., Gebeyehu, S., Memiah, P., \& Desta, M. (2021). Breast self-examination practice and its determinants among women in Ethiopia: A systematic review and meta-analysis. PloS one, 16(1), e0245252.

(23) Yilmaz M., Sayın Y., and Cengiz H., (2017). The Effects of Training on Knowledge and Beliefs About Breast Cancer and Early Diagnosis Methods Among Women. European Journal of Breast Health, Vol. 13(4): 175-182.

(24) Yoshany N., Mihanpour H., Jadgal K. and Dori M., (2016). The Effect of Breast Self-Examination Educational Program on the Knowledge and Performance of Women in Yazd. Journal of Community Health Research; 5(3): 211219. 